\section{GEOLOGY \\ Geometrically Complicated Monogenetic Flow Folds}

Common phenomena observed in gneissic terrains include the remarkable contortions shown by the compositional layers within the gneisses. Some of the more simple deformations have been analysed and accounted for adequately ${ }^{1}$, but the more complicated contortions have been dismissed as 'flow folding', 'plastic folding', etc., with no further note.

Folded gneissic bands and enclosed mafic layers (for example, amphibolites) are often very impersistent, and show little regularity in the disposition of fold axes (crest and trough lines) and axial planes. Such folds have been considered to comprise the class of flow folds ${ }^{2}$. However, I have maintained that the geometrically simple folds resulting from a laminar type of plastic flow more or less perpendicular to marker layers should also be included in this class, and suggested that the more complicated flow folds in both hard rock and soft sediment result from unusual patterns of laminar flow ${ }^{3}$. Thus flow folds were redefined in more general terms as "contortions affecting only incompetent beds, which have thickened and thinned without the aid of ruptures above microscopic levels".

In recent years many studies have been mado of super. imposed fold systems ${ }^{4-8}$, and characteristics of such systems include the development of 'hooks' in the rock distribution, and irregularities in the disposition of the fold axes and axial planes.
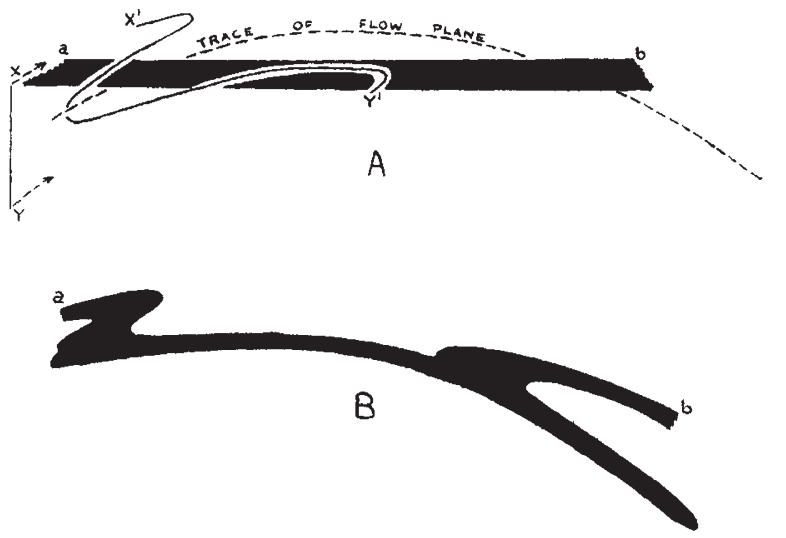

Fig. 1

In amplification of my earlier statements and to introduce a note of caution in concluding multiple folding for geometrically complicated folds, Fig. I shows how monogenetic folds may have peculiarities hitherto often taken to suspect the presence of superimposed folding. In Fig. $1 A$ let deformation proceed by a laminar-type flow along involuted planes parallel to the broken line in the general direction of the marker layer $a b$ (solid shading), so that the imaginary line $X Y$ is displaced to $X^{\prime} Y^{\prime}$. Involution of the flow planes may result from slight variations in pressures, temperatures and chemical compositions. The resulting contortion of the layer $a b$ in a by-and-large isotropic plastic medium is shown in Fig. $1 B$, where 'hooks' and folds facing opposite directions have been developed.

Emyr WiLIIAMS

44 Soberton Avenue,

Heath, Cardiff.

${ }^{2}$ Cannon, R. T., Geol. Mag., 99, 2, 164 (1962).

${ }^{2}$ de Sitter, I. U., Structural Geology (McGraw-Hill, New York, 1956).

Williams, E., Nature, 189, 474 (1961).

- Reynolds, D. L., and Holmes, A., Geol. Mag.. 91, 6, 417 (1954).

Weiss, L. E., Bull. Geol. Soc. Amer., 70, 1, 91 (1959).

- Ramsay, J. G., J. Geol., 68, 1, 75 (1960).

"Carev, S. W., J. Alberta Soc. Petrol. Geol., 10, 3, 95 (1962).

8 'Driscoll, F. S., J. Alberta Soc. Petrol. Geol., 10, 3, 145 (1962).

\section{Recrystallization of Zircon as an Indication of Contact Metamorphism}

ZIrcoN $\left(\mathrm{ZrSiO}_{4}\right)$ is generally regarded as the most refractory accessory mineral present in the common rock types ${ }^{1}$. According to Poldervaart ${ }^{2}$, incipient granulation and recrystallization of zircon when exposed to ultrametamorphic processes can be expected only in a stage as high as the sillimanite grade. Investigations in quartzite xenoliths in the southern norite belt of the Bushveld Igneous Complex of the Transvaal (South Africa), however, indicate definitely that these processes can be caused by usual contact metamorphism and that the foregoing conceptions should be revised.

A zircon concentrate from a thermally reconstituted quartzite slab floating in the Bushveld norite north-west of Pretoria shows a characteristic preponderance of rocrystallized zircons, that is, crystals displaying a rounded or fractured core enveloped in a mostly idiomorphic, transparent shell (Fig. 1). Statistical evaluation of the material revealed that from 300 grains counted $137(45 \cdot 66$ per cent) show clear signs of recrystallization. In a number of others the core is not so easily recognizable, but appears as a cloudy spot, surrounded by a somewhat 'ghostly' outline. A comparison of these metamorphosed quartzites with the 'normal' quartzites of the Pretoria series outside the Bushveld aureole shows that tho latter contain scarcely any zircons displaying recrystallization phenomena ( $<2$ per cent).

The results thus obtained are not difficult to explain. It is self-evident that the rounded or fractured kernels of the recrystallized zircons represent minute zircon 'pebbles' in all stages of attrition, originally representing the bulk of the heavy mineral fraction of a sedimentary rock. Accordingly, these zircons did not originate in this rock; they were merely deposited after having undergone transport, during which they developed their characteristic pebblish or fragmental shape (cf. Fig. 1). Speaking in genetic terms, they cannot be referred to as primary constituents of the rock formed here in situ, but only as secondary or allogenic components derived from outside sources and dumped together with other sedimentary detritus finally constituting an arenaceous rock.

Their host-rock later being subjected to contact metamorphism, these zircons suffered thermal recrystallization, that is, a stage of secondary growth resulting in the development of an outer shell which is mostly water-clear and idiomorphic, showing often a model-shaped crystal form with sharply pointed pyramidal terminations (Fig. 1). In contrast to the parent detrital grains, these outgrowths were formed in place; hence they are primary or authigenic constituents of the rock. The cores enclosed

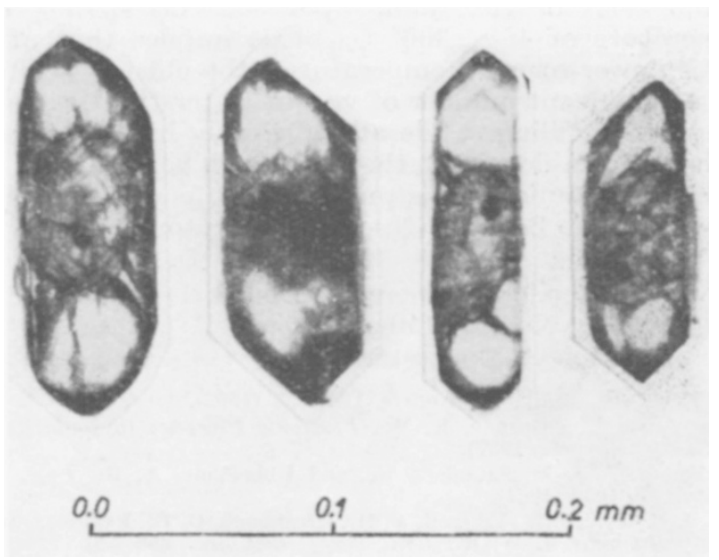

Fig. 1. Recrystallized zircons from a metamorphosed quartzite in the Bushveld norite north of Vissershoek (north-west of Pretoria) 